\title{
ENSAIO FOTOGRÁFICO Cenas do trabalho em Yumani: transformações em uma comunidade tradicional
}

\author{
Tamires Eidelwein ${ }^{1}$ \\ Gabriel Eidelwein Silveira ${ }^{2}$ \\ Universidade Federal do Piauí
}

Resumo: Trata-se de um ensaio fotográfico, realizado em trabalho de campo, na comunidade Yumani, na Isla del Sol, no lado boliviano do Lago Titicaca. As fotografias enfocam cenas do trabalho, no cotidiano da comunidade, buscando evidenciar as formas tradicionais de trabalho cooperativo indígenas (pastoreio da alpaca e da ovelha, agricultura em socalcos, obras em mutirão etc.), que sobrevivem às transformações trazidas pela economia competitiva do turismo.

Palavras-chave: Yumani; trabalho; comunidade.

\footnotetext{
${ }^{1}$ Mestranda em Antropologia na Universidade Federal do Piauí (PPGAnt/UFPI), Bolsista da Coordenação de Aperfeiçoamento de Pessoal de Nível Superior (CAPES).

${ }^{2}$ Doutor em Sociologia pela Universidade Federal do Rio Grande do Sul (PPGS/UFRGS). Professor permanente do Programa de Pós-Graduação em Sociologia da UFPI (PPGS/UFPI).
} 


\title{
Scenes from work in Yumani: transformations in a traditional Community
}

\begin{abstract}
This is a photographic essay, carried out in fieldwork, in the Yumani community, at Isla del Sol, on the Bolivian side of Lake Titicaca. The photographs focus on scenes of work, in the daily life of the community, seeking to highlight the traditional forms of indigenous cooperative work (alpaca and sheep grazing, terraced agriculture, collective work, etc.), which survive the transformations brought about by the competitive economy of tourism.
\end{abstract}

Keywords: Yumani; work; community.

\section{Escenas del trabajo en Yumani: transformaciones en una comunidad tradicional}

Resumen: Este es un ensayo fotográfico, realizado en un trabajo de campo, en la comunidad Yumani, en la Isla del Sol, en el lado boliviano del lago Titicaca. Las fotografías se enfocan en escenas de trabajo, en la vida cotidiana de la comunidad, buscando resaltar las formas tradicionales de trabajo cooperativo indígena (pastoreo de alpacas y ovejas, agricultura en terrazas, trabajo colectivo, etc.), que sobreviven a las transformaciones provocadas por la economía competitiva del turismo.

Palabras clave: Yumani; trabajo; comunidad. 


\begin{abstract}
$\mathrm{A}$ comunidade Yumani está localizada na parte sul da Isla del Sol, no Lago Titicaca, na Bolívia. Os habitantes, em sua maioria de origem aymara, têm vivenciado dramáticas transformações em seu modo de vida nas últimas duas décadas. A instalação da energia elétrica, no início dos anos 2000, propiciou o desenvolvimento do turismo, que rapidamente se tornou a principal atividade econômica na Ilha. Acostumada a um modo de vida tradicional, baseado na agricultura familiar, na pecuária, na pesca e no artesanato, Yumani observa a explosão da atividade turística, com a intensificação da construção de pousadas e restaurantes, atividades de guia, comércios voltados a turistas, como as tiendas de artesanias, e outras atividades relacionadas. $\mathrm{O}$ trabalho familiar, voltado à subsistência, e o tradicional trabalho comunitário colaborativo subsistem, ao lado da emergente economia competitiva em moldes capitalistas.

O turismo passa a configurar importante fonte de ingressos para os comunarios da ilha, que, antes dele, possuíam uma economia quase totalmente alheia às trocas monetárias. Algumas atividades são exploradas diretamente pelas famílias, como os restaurantes e as pousadas, enquanto outras são uma fonte de arrecadação propriamente comunitária, tais como os ingressos cobrados dos turistas, que visitam a ilha, logo ao desembarcarem em Yumani. Tais recursos coletivos viabilizam obras comunitárias, realizadas em regime de mutirão, conforme determinadas pelas autoridades eleitas da comunidade. O mutirão é uma forma de trabalho tradicional indígena, que sobrevive à emergência da economia competitiva, atestando a força dos laços de solidariedade no seio da comunidade. Embora os nativos preservem uma vida rústica e campesina, o turismo propiciou à Ilha do Sol um incremento nos níveis de acesso a tecnologias, tais como internet e celular, além de um relativo conforto. No entanto, estas transformações têm impactado fortemente a cultura, aumentando a distância entre os valores tradicionais e modernos, entre as gerações.
\end{abstract}

Recebido em 8 de março de 2020.

Aceito em 8 de agosto de 2020. 


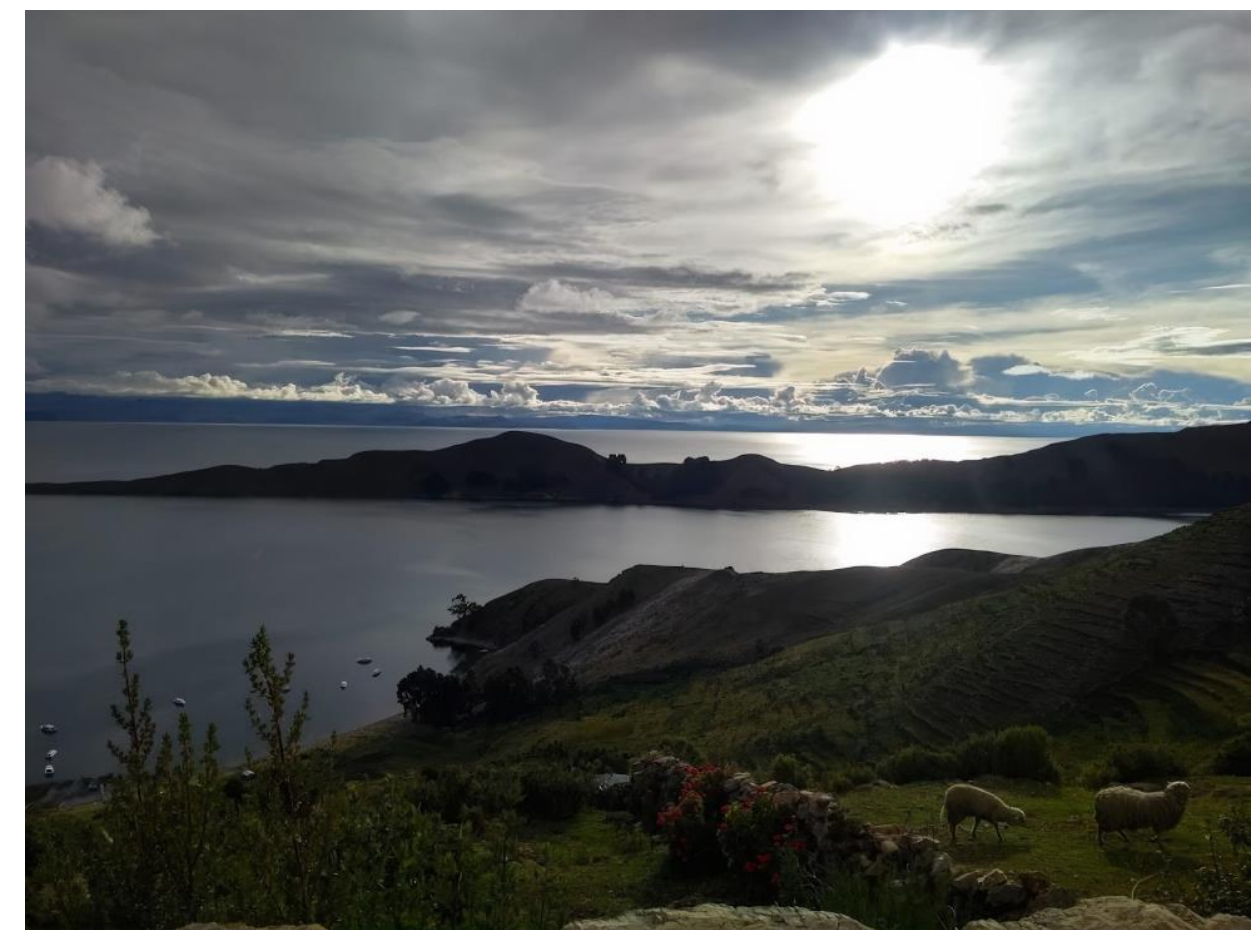

Foto 1 - Final de tarde em Yumani: vista do Lago Titicaca, a partir da parte alta da comunidade, com ovelhas pastando e plantios em socalcos (2020).

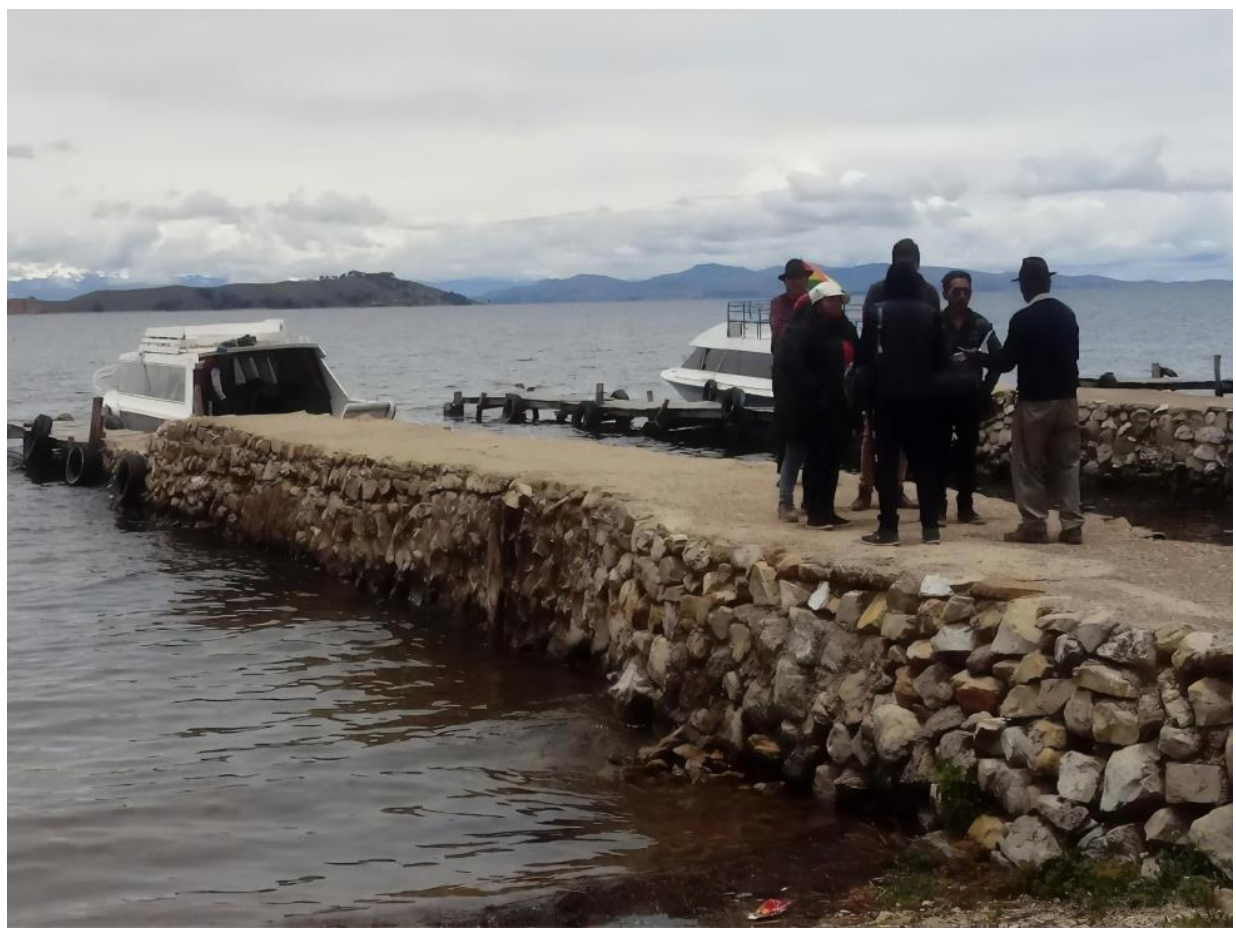

Foto 2 - Turistas pagam o ingresso ao desembarcarem no porto em Yumani (2020). 


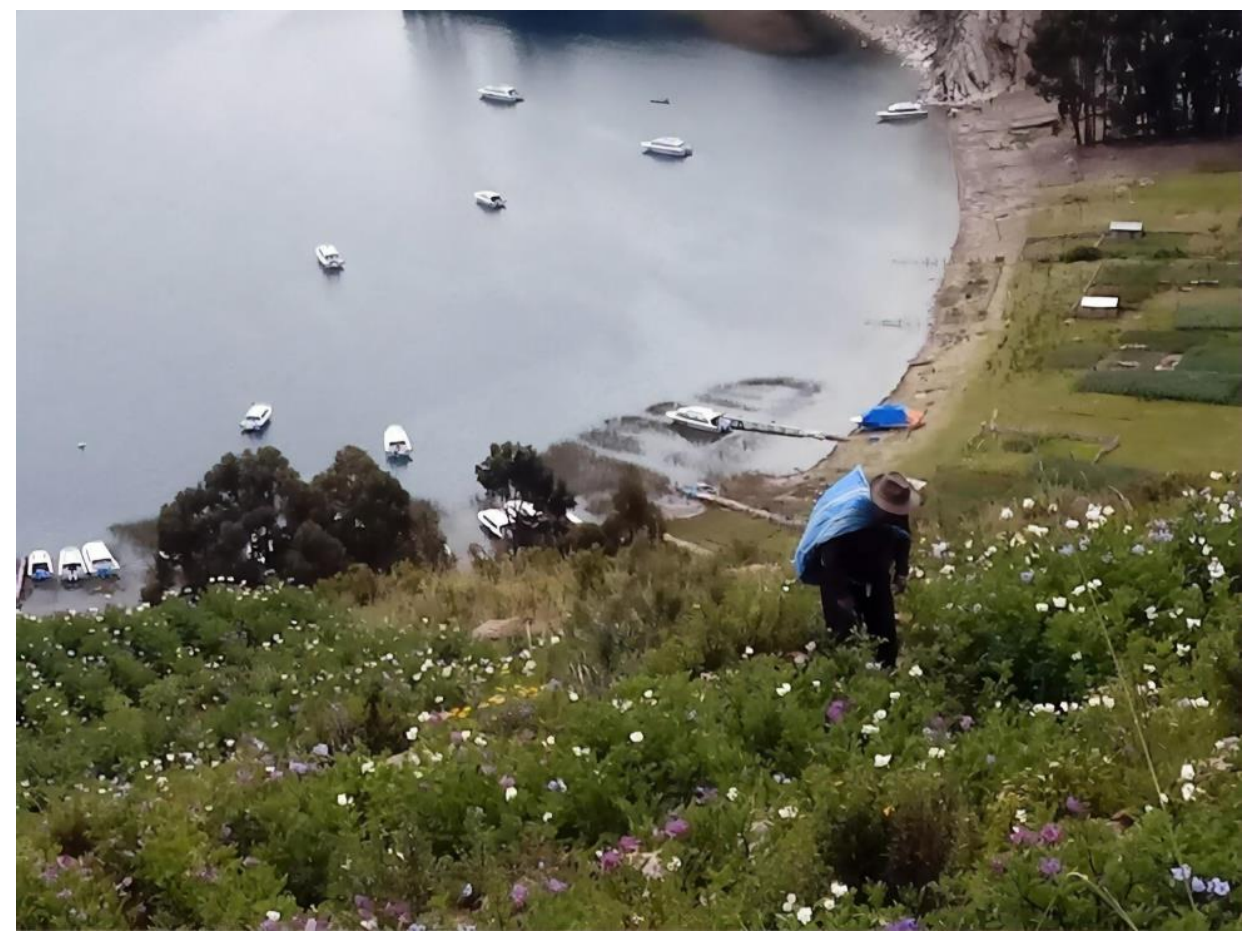

Foto 3 - Agricultor aymara na lavoura em socalco, com a vista de um porto secundário de Yumani ao fundo (2020).

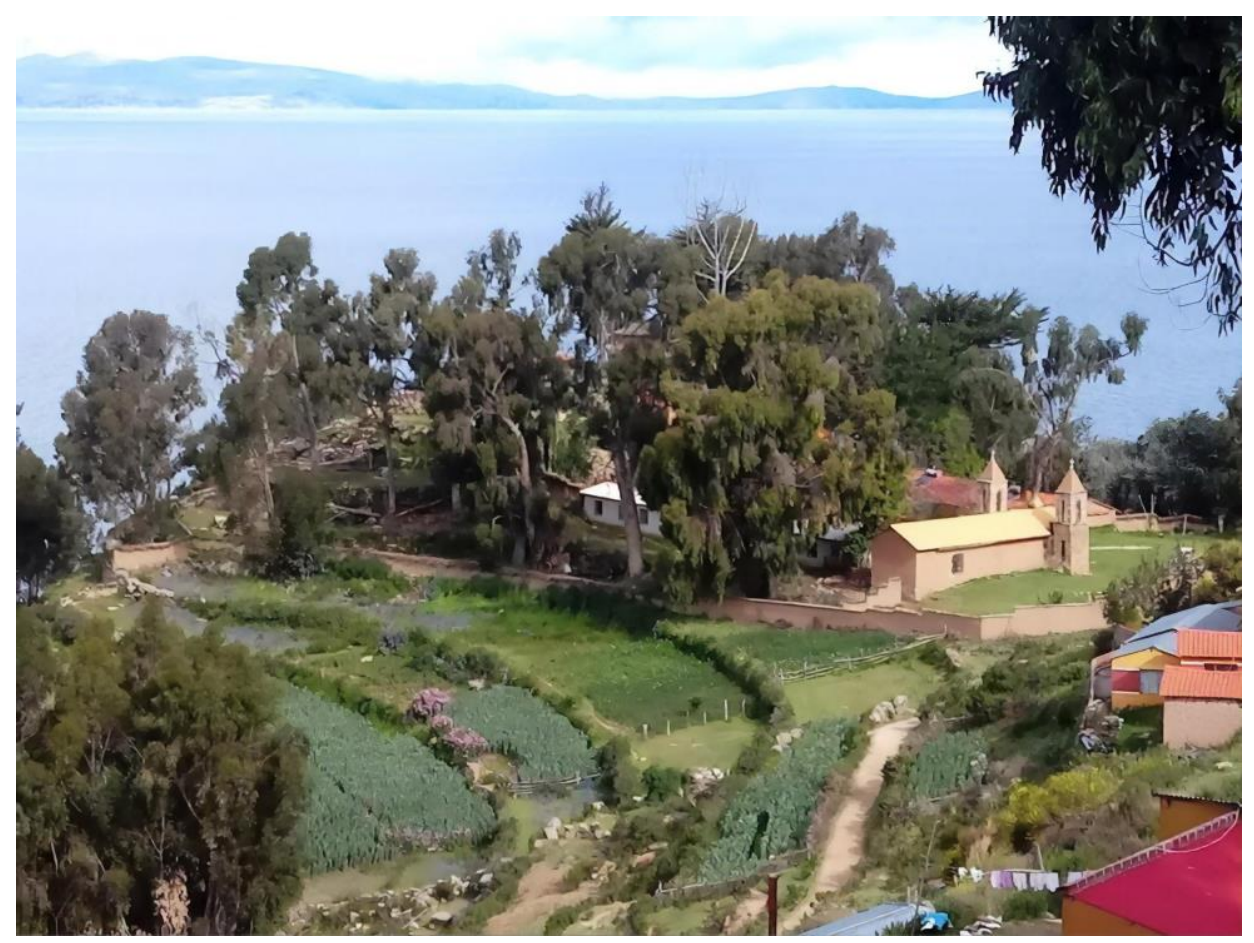

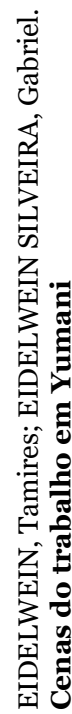

Foto 4 - Tradicional técnica indígena de terraceamento para plantio em terrenos íngremes. Ao fundo, a Igreja de Santo Antônio (2020). 


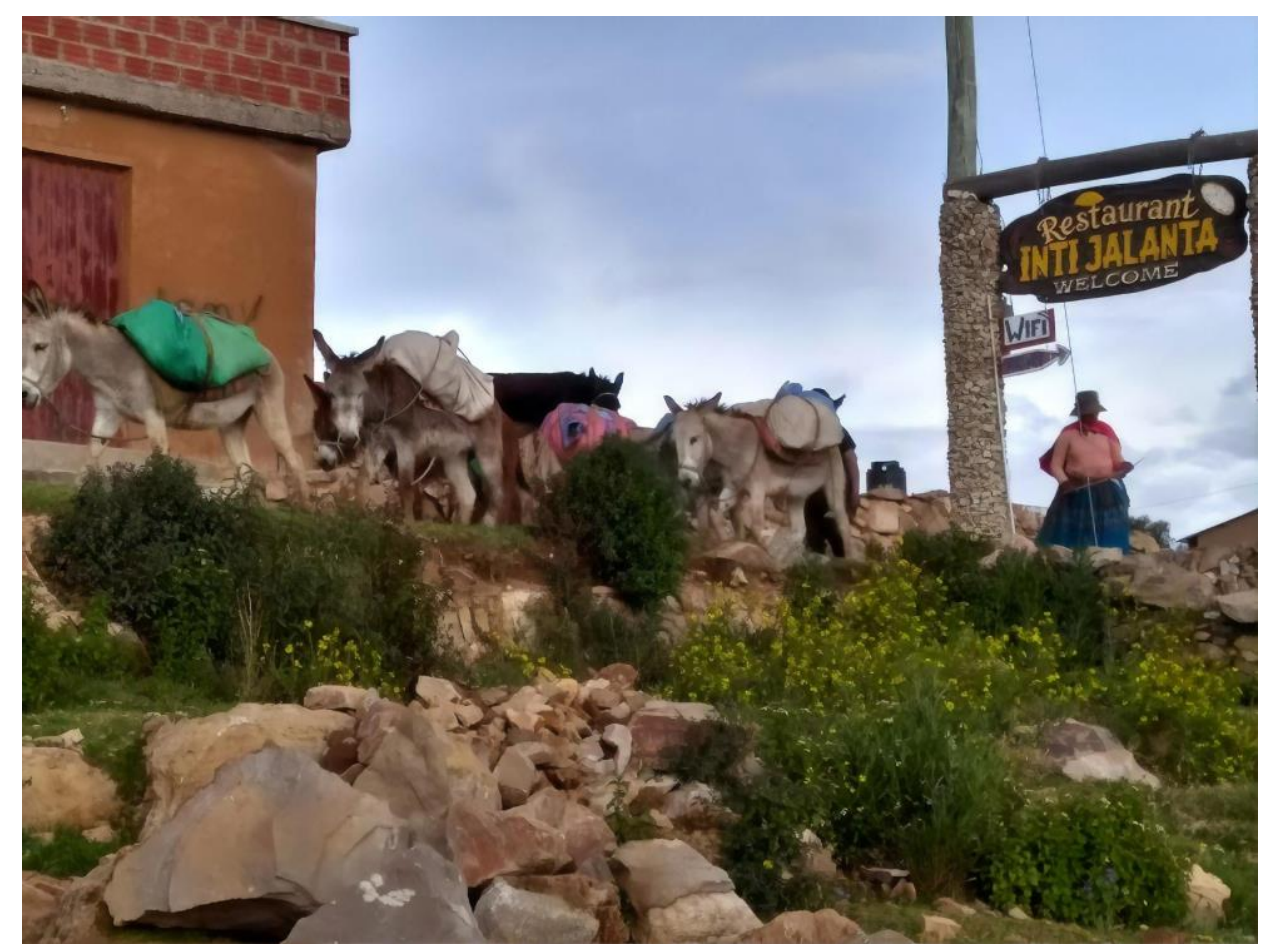

Foto 5 - Os burros fazem o trabalho pesado. No detalhe, mulher com vestimentas tradicionais de chola, ao lado de placa de restaurante turístico oferecendo conexão wifi (2020).

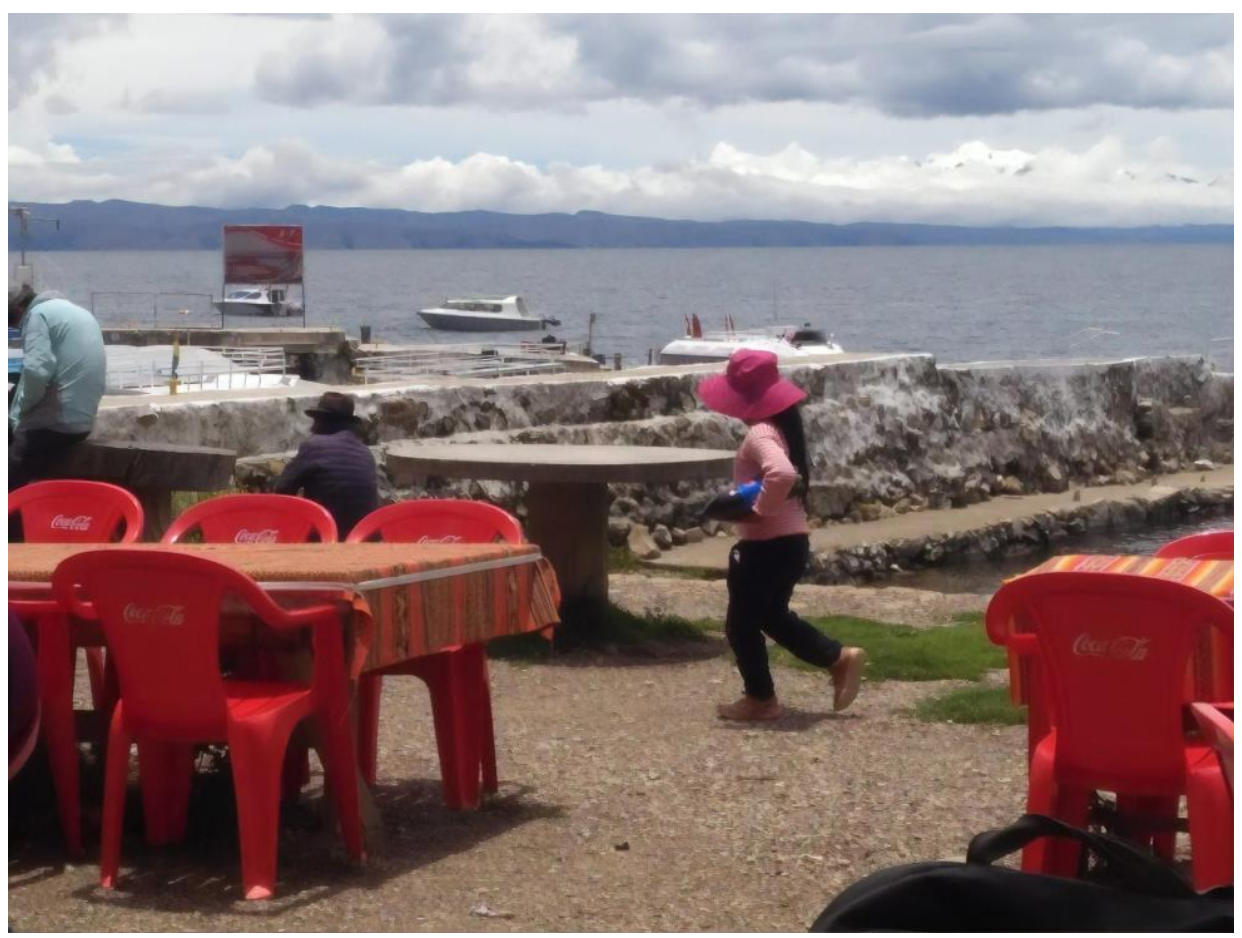

Foto 6 - Hora do almoço: menina aymara, no porto em Yumani, carregando uma garrafa de refrigerante (2020). 


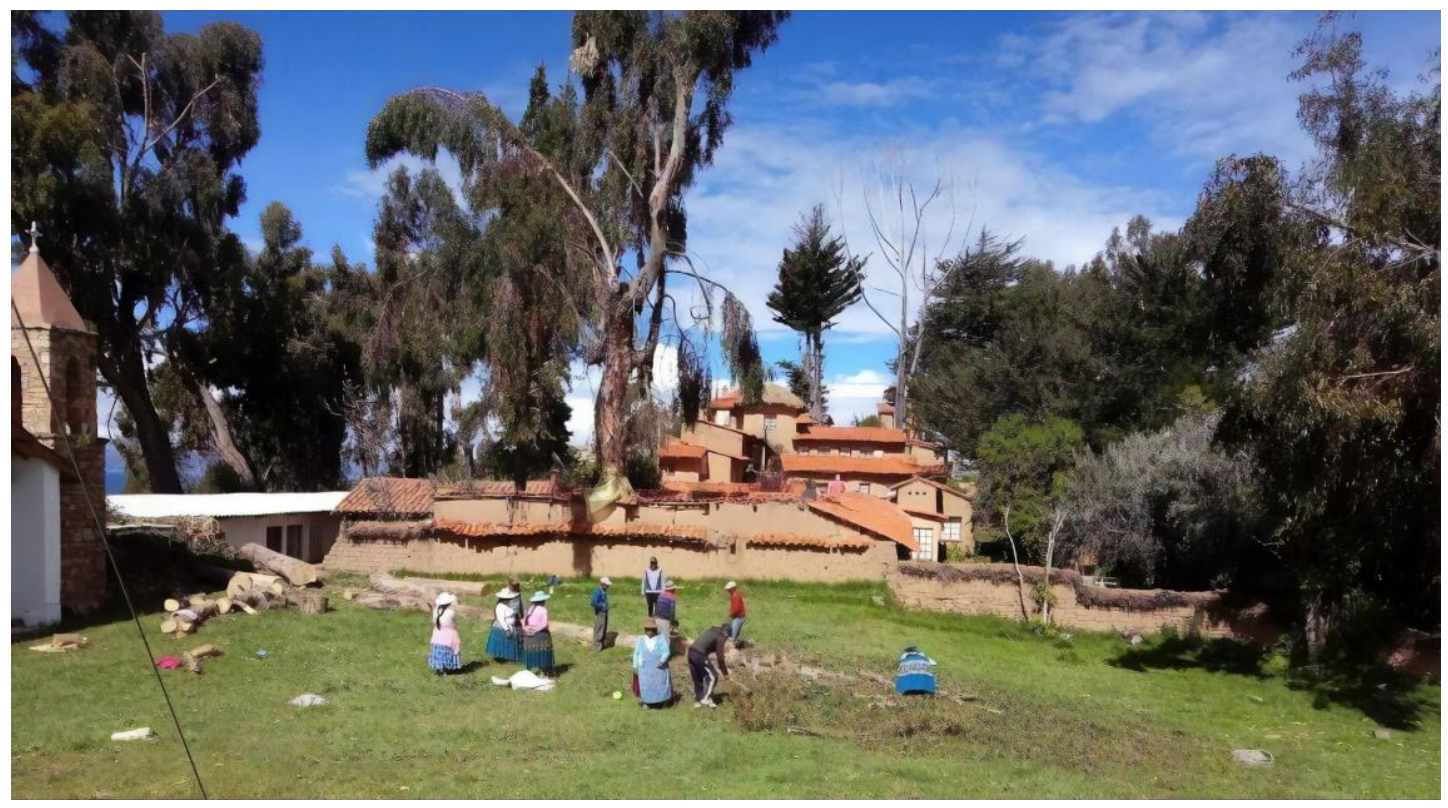

Foto 7 - Mutirão: homens e mulheres participam do trabalho comunitário colaborativo (2020).

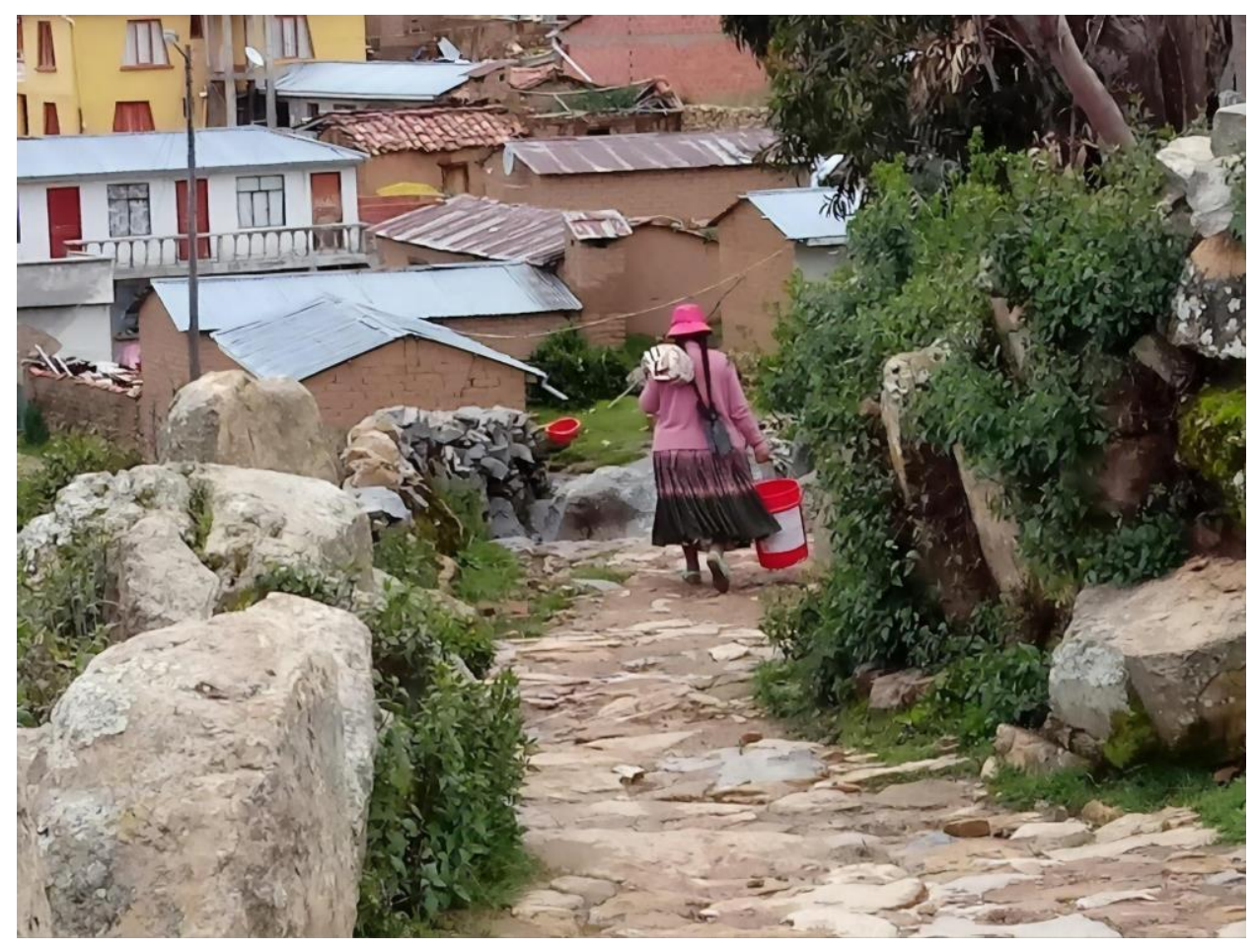

Foto 8 - Mulher aymara, com roupas tradicionais de chola, carrega balde de água ladeira abaixo (2020). 


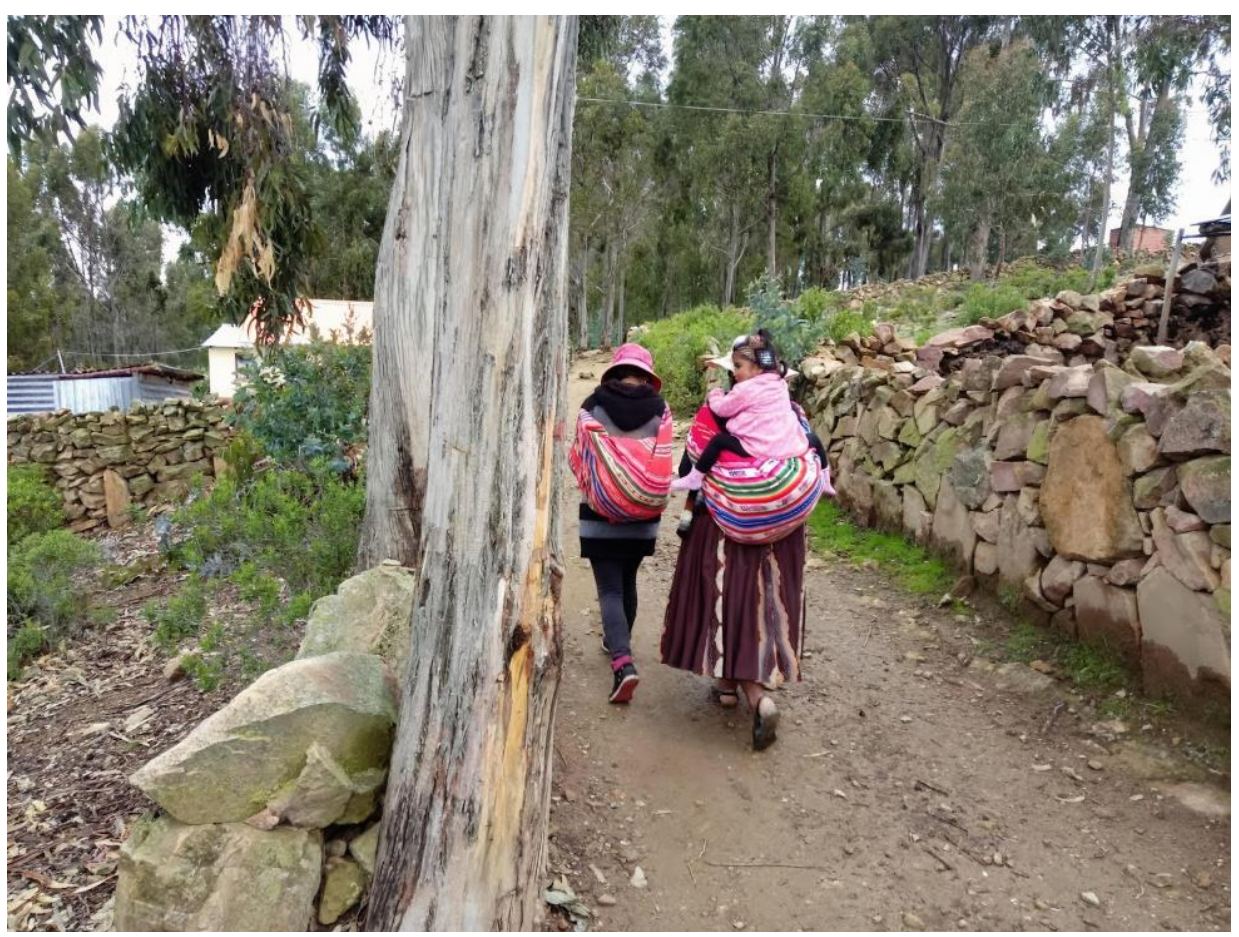

Foto 9 - Mãe e filha carregam os tradicionais awayos indígenas. A mãe, com uma bebê menina no aguayo, veste uma pollera tradicional de chola, enquanto a filha se veste em trajes comuns aos jovens urbanos (2020).

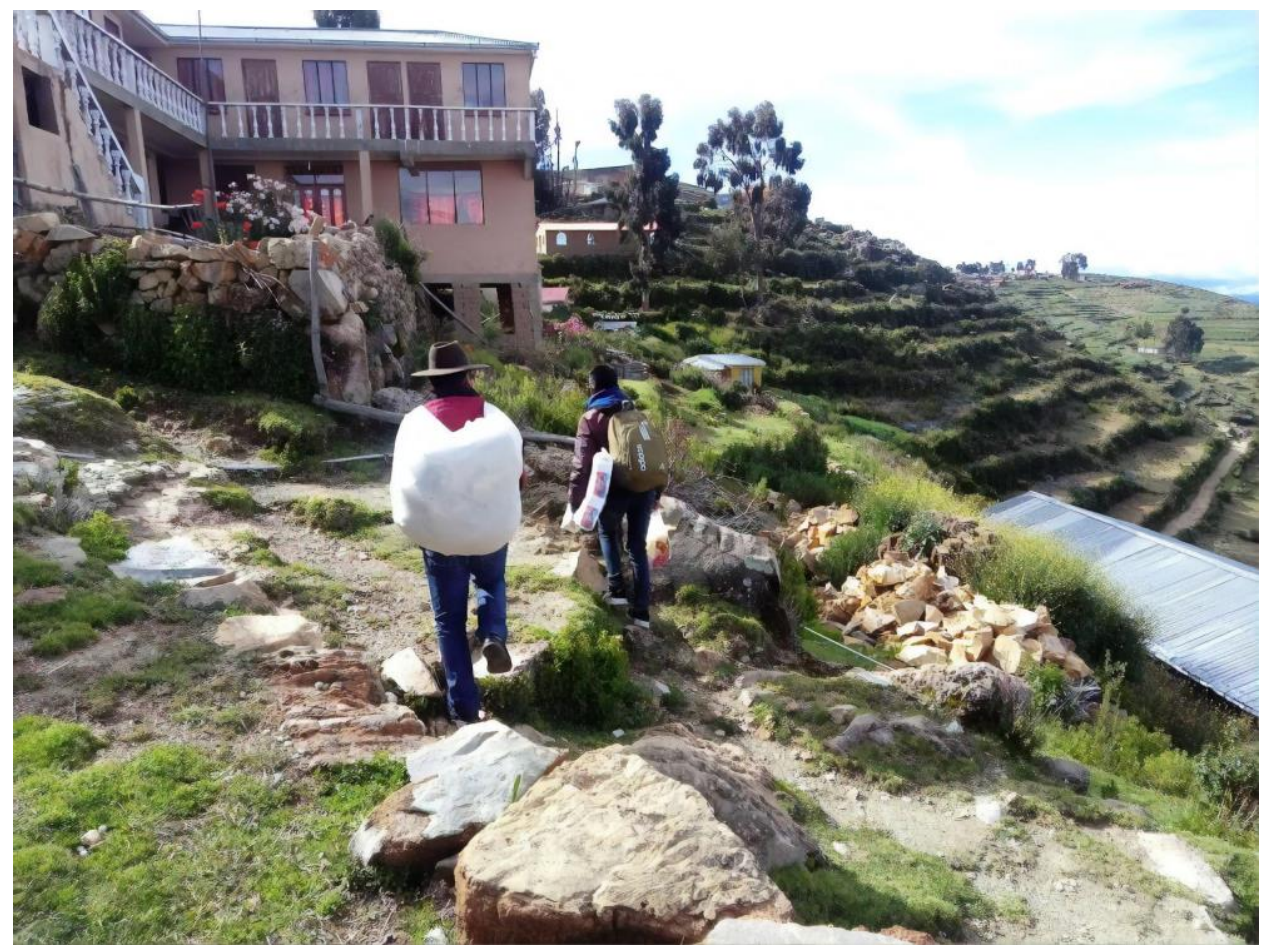

Foto 10 - Pai e filho transportam suprimentos e mercadorias para a pousada da família. Ao fundo, lavouras de terraceamentos (2020). 